\section{Cellulose-based Coatings as Carriers for Candida guillermondii and Debaryomyces sp. in Reducing Decay of Oranges}

\author{
R. Potjewijd \\ Landbouwuniversiteit Wageningen Agricultural University, Wageningen, \\ The Netherlands
}

\author{
M.O. Nisperos \\ Australian Food Industry Science Center, Department of Agriculture, \\ Werribbee, Australia
}

\author{
J.K. Burns and M. Parish \\ Citrus Research and Education Center, University of Florida, Lake Alfred, \\ FL 33850
}

\section{E.A. Baldwin ${ }^{1}$ \\ U.S. Department of Agriculture, Agricultural Research Service, Citrus and Subtropical Products Laboratory, P.O. Box 1909, Winter Haven, FL 33883-1909 \\ Additional index words. biocontrol agent, yeast, Citrus sinensis, Penicillium digitatum, carboxymethylcellulose, methylcellulose, hydroxypropylcellulose}

\begin{abstract}
Varying the cellulose component of coating formulations affected the survival of two yeast biocontrol agents, Candida guillermondii (Castelani) Langeron and Guerra strain US7 and Debaryomyces sp. strain 230, when these yeasts were incorporated into the coating. Using methylcellulose as the main film-former gave the most recovery of the yeasts after an incubation period for both strains. Significant control of decay on naturally infected 'Pineapple' and 'Valencia' oranges [Citrus sinensis (L.) Osb.] was demonstrated for US7 in a methylcellulose-based coating for the first 2 to 4 weeks of storage at $16 \mathrm{C}$ and $90 \%$ relative humidity. During this time, US7 in methylcellulose formulations was similar in decay control to a commercial shellac coating with imazalil at $2000 \mathrm{mg}^{-1 i t e r^{-1}}$. A US7 concentration of at least $10^{5}$ colony-forming units $/ \mathrm{cm}$ was maintained on the coated fruit surface of 'Valencia' oranges for 3 weeks of storage. Suppression of decay by US7 was improved by the addition of glucose and calcium chloride to the coating formulation. Although nearly equal in concentration recovered, Debaryomyces strain 230 was not as effective as US7 in disease suppression of 'Pineapple' oranges. The addition of US7 to Nature Seal, a coating material made with methylcellulose, had neither a quantitative nor a qualitative effect on the pathogen population compared to the same formulation without the antagonist. Chemical name used: 1-[2-(2,4-dichlorophenyl)-2-(2-propenyloxy)ethyl]$1 H$-imidazole (imazalil).
\end{abstract}

Green mold and blue mold caused by Penicillium digitatum Sacc. and $P$. italicum Wehmer, respectively, and sour rot caused by Geotrichum candidum Link account for most postharvest losses of citrus fruit worldwide

Received for publication 13 Mar. 1995. Accepted for publication 9 Aug. 1995. Mention of a trademark or proprietary product is for identification only and does not imply a guarantee or warranty of the product by the U.S. Dept. of Agriculture (USDA). All programs and services of the USDA are offered on a nondiscriminatory basis without regard to race, color, national origin, religion, sex, age, marita status, or handicap. We thank Eldon Brown for advice and use of laboratory equipment, Charles Wilson for isolate US7 and 230, and Lorrie Friedrich and Holly Sisson for excellent technical support. The cost of publishing this paper was defrayed in part by the payment of page charges. Under postal regulations, this paper therefore must be hereby marked advertisement solely to indicate this fact.

${ }^{1}$ To whom reprint requests should be addressed.
(Bancroft et al., 1984). These diseases have been traditionally controlled by chemical fungicides, often applied in a wax or coating, in combination with physical means, such as cold storage. However, fungicide efficacy is frequently reduced by the development of resistant strains of pathogens. In addition, public awareness and concern regarding pesticide residues in food has greatly increased in recent years (Droby et al., 1990). These findings emphasize the need to find alternative means for controlling postharvest diseases of citrus.

Waks et al. (1985) demonstrated that waxing itself may reduce mold rots. In recent years, biological control of postharvest diseases of fruit also has received considerable attention. Antagonists for citrus fruit pathogens have been isolated by Singh and Deverall (1984), Wilson and Chalutz (1989), Huang et al. (1992), and Smilanick and Denis-Arrue (1992). Among these antagonists, a yeast, Candida guillermondii (Castelani) Langeron and Guerra (teleomorph Pichia guilliermondii Wickerham) strain US7 (US7) [previously identified as Debaryomyces hansenii (Zoph) Lodder and Kreger-van Rij, McLaughlin et al. (1990)], exhibited characteristics that made it a good candidate for biocontrol of postharvest diseases (Droby et al., 1989; Wilson and Chalutz, 1989). This yeast, originally isolated from the surface of lemon fruit [Citrus limon (L) Burm. f.], was highly antagonistic under laboratory conditions against several citrus wound pathogens, did not produce antibiotics in culture, was persistent on the fruit and wound surface, was relatively resistant to postharvest fungicides, and is commonly found on food products (Chalutz and Wilson, 1990). Competition for nutrients at the wound site, which inhibit spore germination and germ tube elongation by the pathogens, may be the major mode of antagonism (Wilson et al., 1991). A second yeast antagonist, described as Debaryomyces sp. strain 230 (230), was recently isolated from the surface of apple fruit (Malus domestica Borkh.) and also exhibited antifungal activity (unpublished).

To be commercially acceptable, the application of a biocontrol agent must be compatible with packinghouse operations. Citrus fruit normally go through a waxing step where fungicides are often added, which could be an ideal stage for application of an antagonist. An edible coating, Nature Seal (EcoScience Produce Systems, Orlando, Fla.), based on cellulose derivatives, was recently developed at the U.S. Dept. of Agriculture (USDA), Agricultural Research Service (Nisperos-Carriedo and Baldwin, 1993, 1994). In preliminary studies, Nature Seal formulations with sodium carboxymethylcellulose were inoculated with US7 and applied to oranges with no resulting decay control (unpublished). McGuire (1994), however, tested the compatibility of US7 in six commercial citrus coatings and in Nature Seal with methylcellulose, all of which were applied to heat-treated grapefruit (Citrus paradisi Macf.). Only Nature Seal and FMC 705 (FMC Corp., Lakeland, Fla.) were compatible with yeasts; these were the only coatings tested that did not contain resins and their accompanying harsh solvents. Nature Seal, in particular, appeared to offer a nutritional component that supported yeast populations. Use of waxes or fruit coatings as carriers of biocontrol agents may help bind the biocontrol agent to the fruit. Fruit coatings could also be formulated to select for and promote growth of the antagonist.

The present research was designed to evaluate the use of cellulose-based coating formulations as carriers for the yeast antagonists US7 and 230 and the efficacy of these antagonists on naturally infected oranges. The effect of coating formulations, based on various types of cellulose, on the viability of the two antagonists was assessed at 26 and $13 \mathrm{C}$.

\section{Materials and Methods}

Preparation of coatings, plate media, and dilution blanks. Formulations of either sodium carboxymethylcellulose, methylcellu- 
lose, or hydroxypropylcellulose at $2 \%$ cellulose $(\mathrm{w} / \mathrm{v})$ were prepared. Other ingredients in coating formulations included water, a plasticizer, an acidulant, and, in certain formulations, glucose and calcium chloride at $0.2 \%$ and $0.22 \%(\mathrm{w} / \mathrm{v})$, respectively (Nature Seal) (Nisperos-Carriedo and Baldwin, 1993, 1994). The $\mathrm{pH}$ of the coatings was 3.0; solids constituted $3.0 \%$ to $3.5 \%$.

Plate count agar or potato dextrose agar (PDA) (Difco, Detroit) were prepared as directed by the manufacturer. The PDA medium was made semi-selective for yeasts by addition of tartaric acid to a $\mathrm{pH}$ of 3.5 .

Nine milliliters of a $0.1 \%$ solution of bactopeptone was pipetted into dilution tubes that were sealed and autoclaved for $20 \mathrm{~min}$ for subsequent use in serial dilutions of suspended antagonists in coating formulations.

Antagonists. Cultures of US7 and 230 were obtained from Charles Wilson of the USDA Appalachian Fruit Research Station, Kearneysville, W.Va., and were stored on malt yeast agar at $5 \mathrm{C}$. Before the experiments were started, the yeasts were grown on acidified PDA for at least 3 days, then transferred to 250-ml flasks containing $50 \mathrm{ml}$ of nutrient yeast dextrose broth (NYDB) $[8 \mathrm{~g}$ nutrient broth, $5 \mathrm{~g}$ yeast extract, $5 \mathrm{~g} \mathrm{D}$-glucose in 1 liter deionized (DI) water] and incubated on a shaker at $29 \mathrm{C}$ for $48 \mathrm{~h}$. The growth medium was removed by centrifugation $(13,000 \times g$ for 10 $\min$ ) and the cultures were washed twice with sterile DI water. Cell pellets were resuspended in sterile DI water at a concentration of $10^{8}$ colony-forming units (cfu)/ml. Population densities were calculated from absorbance at 350 $\mathrm{nm}$ and enumerated by spiral-plating on acidified PDA (Spiral System Instruments, Bethesda, Md.). PDA plates were incubated at $26 \mathrm{C}$ for 4 days, and colonies were counted using a laser colony scanner (model 500A; Spiral System Instruments).

Survival of antagonists in coatings. For recovery in liquid coatings at $26 \mathrm{C}$, yeasts were first cultured at $29 \mathrm{C}$ for $48 \mathrm{~h}$ since Chalutz and Wilson (1990) reported that the inhibitory activity of US7 against Penicillium digitatum was greatest after incubating for $48 \mathrm{~h}$ in NYDB, as opposed to shorter or longer incubation periods. The antagonists were then washed with DI water, and wet antagonist US7 cells were suspended in DI water to give a concentration of $2.3 \times 10^{8} \mathrm{cfu} / \mathrm{ml}$, which was equivalent to an absorbance of 1.6 at $350 \mathrm{~nm}$. The 230 cells, treated in the same way, were suspended at $1.7 \times 10^{8} \mathrm{cfu} / \mathrm{ml}$ with an absorbance of 1.4 . Two milliliters of antagonist suspensions or sterile DI water were added to $8 \mathrm{ml}$ of coating formulated with $2 \%$ sodium carboxymethylcellulose (CMC), methylcellulose (MC), or hydroxypropylcellulose (HPC); mixed; and stored at $26 \mathrm{C}$. The coating formulations were at $80 \%$ of the undiluted strength after addition of the suspensions. Recoveries of the yeasts (average of two experiments) were determined after storage at $26 \mathrm{C}$. After 1, 4, 7, and $24 \mathrm{~h}$, a sample was taken and an appropriate serial dilution was spiral-plated on acidified PDA. The plates were incubated at $26 \mathrm{C}$ for 2 days. The experiment was performed twice.
In a subsequent test, $2 \mathrm{ml}$ of antagonist suspension was added to $8 \mathrm{ml}$ of coating or 8 $\mathrm{ml}$ of $0.1 \%$ bacto-peptone, and a $0.1-\mathrm{ml}$ sample was applied to sterile disks of Whatman No. 1 filter paper. The filters were dried under a sterile hood and stored in petri dishes at 13C, which is used commercially for oranges. Immediately after suspension and after $6,12,16$, 20 , and 28 days, two filters were washed separately (in $10 \mathrm{ml}$ of $0.1 \%$ bacto-peptone) $30 \mathrm{~min}$ on a circular shaker at $200 \mathrm{rpm}$. The wash water was spiral-plated on acidified PDA.

Application of antagonists to oranges. Freshly prepared yeast suspensions were added to Nature Seal formulated with $2 \% \mathrm{MC}$, since this cellulose derivative was determined to be the best carrier for the antagonists. Naturally infected 'Pineapple' or 'Valencia' oranges were coated with MC formulations with or without antagonists and with a commercial shellac-based coating (FMC 360HS; FMC Corp.) based on alkali-soluble resins (SH) commonly used in citrus packinghouses. As reported by McGuire (1994), yeasts used in this study were not compatible with the $\mathrm{SH}$ coating (data not shown) and, therefore, were not applied to fruit in SH. Instead, the MC- and $\mathrm{SH}$-based coatings were applied with and without imazalil, a fungicide commonly used on citrus fruit. 'Valencia' oranges also were treated with US7 in MC coatings formulated with added nutrients $(0.2 \%$ glucose and $0.22 \%$ calcium chloride) and with an aqueous suspension of US7.

Naturally infected 'Pineapple' or 'Valencia' oranges were obtained from a local packinghouse in Winter Haven, Fla., sorted, washed in $2 \%$ sodium orthophenyl phenate (SOPP), dried, graded, and stored overnight at $25 \mathrm{C}$. The fruit were coated the following day using a nonrecovery drip application on revolving brushes presaturated with treatment suspension. Brushes were washed with water and spin-dried between treatments. All coatings were applied at $80 \%$ of undiluted strength after incorporation of DI water, yeast suspension, or imazalil. Oranges were conveyed through a drier (49C), packed in commercial fruit fiberboard boxes, and stored at $16 \mathrm{C}$ with $90 \%$ relative humidity $(\mathrm{RH})$ for 4 weeks. Each treatment contained four to five boxes of 50 oranges each. After coating, the initial antagonist concentration on the surface of 'Pineapple' orange fruit was $1.3 \times 10^{6} \mathrm{cfu} / \mathrm{cm}^{2}$ for US7 and $6.0 \times 10^{6} \mathrm{cfu} / \mathrm{cm}^{2}$ for 230 . The initial concentration on the surface of coated 'Valencia' oranges for US7 treatments was $2.5 \times 10^{6} \mathrm{cfu} / \mathrm{cm}^{2}$. Controls consisted of washed-uncoated oranges. A set of unwashedunwaxed fruit (therefore not treated with SOPP) also was stored for comparison to the washeduncoated controls.

The fruit were examined weekly and the percentage of decay (due to natural infection) evaluated. Data were analyzed for variance, and means were compared using Duncan's multiple range test at $P \leq 0.05$ (SAS Institute, Cary, N.C.). Three sound fruit from the antagonist treatments were sampled by washing each $30 \mathrm{~min}$ in $100 \mathrm{ml} 0.1 \%$ bacto-peptone on a shaker at $200 \mathrm{rpm}$. The wash water was plated on acidified PDA, and colonies of yeasts were counted. Colony counts were related to the surface area of the washed fruit, calculated from their diameter. Other microorganisms were characterized by gram staining (manufacturer's directions; BBL Microbiology Systems, Cockeysville, Md.) and microscopy.

\section{Results and Discussion}

Survival of US7 and 230 in cellulose formulations. Recovery of antagonists was determined in cellulose formulations (Fig. 1) and was more dependent on the type of cellulose than on the type of antagonist added; however, US7 seemed to be more tolerant of the coatings than 230. Nature Seal made with MC gave the highest recovery. After $24 \mathrm{~h}$, the concentration of US7 and 230 in MC had dropped from $2.8 \times 10^{7}$ to $1.0 \times 10^{6} \mathrm{cfu} / \mathrm{ml}$ and $5.0 \times 10^{5} \mathrm{cfu} / \mathrm{ml}$, respectively. CMC was not compatible with the yeasts, and after $4 \mathrm{~h}$, populations had dropped to $5.4 \times 10^{5}$ and $2.0 \times$ $10^{4} \mathrm{cfu} / \mathrm{ml}$ for US7 and 230, respectively. After $24 \mathrm{~h}$, acidophilic gram-negative rods predominated and were present at $5.0 \times 10^{3}$ $\mathrm{cfu} / \mathrm{ml}$, which increased to $2.0 \times 10^{7} \mathrm{cfu} / \mathrm{ml}$ at $48 \mathrm{~h}$. The presence of gram-negative rods indicated a shift in microbial populations, perhaps at the expense of the antagonist yeasts. Incompatibility of US7 with CMC may explain why decay control was absent when US7 was applied to oranges in Nature Seal made with CMC in preliminary studies. In HPC, the concentration of both antagonists decreased after the first $4 \mathrm{~h}$.

Coatings also were dried on filter paper and stored at $13 \mathrm{C}$ to simulate the conditions of dry coatings on the surface of fruit stored commercially between 10 and $16 \mathrm{C}$. Results (Fig. $2 \mathrm{~A}$ and B) were similar to those for yeasts in liquid coatings (Fig. 1). Highest recovery was generally in the $0.1 \%$ bactopeptone. Among the coating treatments, Nature Seal with MC again had the highest recovery for US7 and 230. Coating with CMC gave the lowest recovery, with US7 showing a greater capability to survive in the coatings than 230. Both antagonists were recovered in the MC coating after 12 days. None of the dried coatings showed contamination with gram-negative rods or other evidence of a major shift in microbial population, unlike in the previous experiment.

Application of the antagonists on oranges. After 1 week of storage at $16 \mathrm{C}$ with $90 \% \mathrm{RH}$, only US7 in the coating made with MC was effective in reducing decay on 'Pineapple' oranges compared with uncoated fruit (Table 1). After 2 weeks, all treatments, except MC alone, controlled the incidence of decay compared with the uncoated control. Treatments containing imazalil appeared most effective, but were not significantly different from the commercial SH coating alone or MC with US7 or 230 . After 3 weeks of storage, only treatments with imazalil showed significant reduction in decay compared with uncoated fruit with the addition of the commercial SH coating in the fourth week. Oranges treated with yeasts, in particular US7, generally developed 


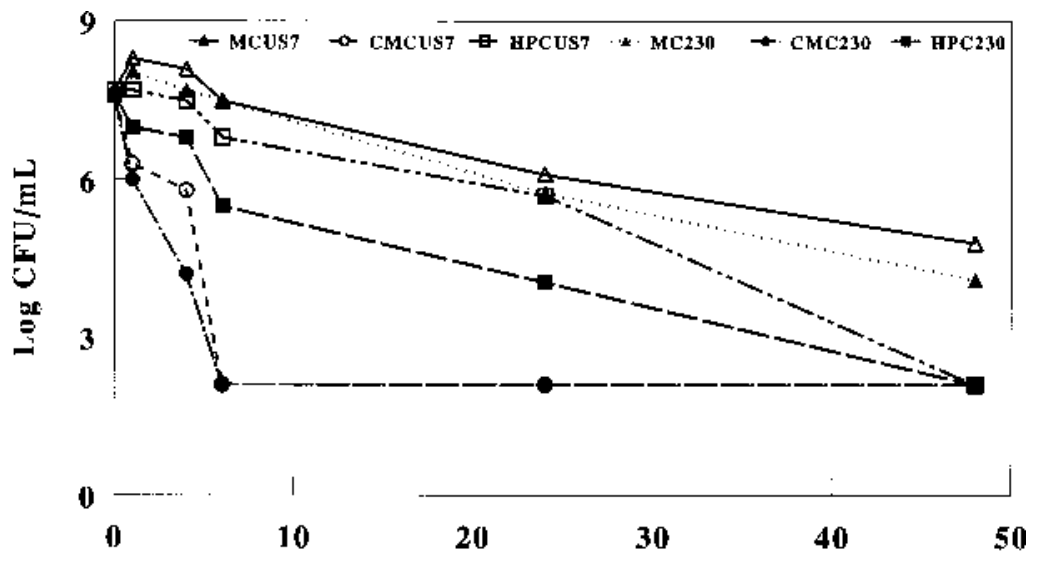

Time (hr)

Fig. 1. Recovery at 26C of Candida guillermondii strain US7 and Debaryomyces sp. strain 230 in liquid Nature Seal formulations made with $2 \%$ methylcellulose (MC), carboxymethylcellulose (CMC), or hydroxypropylcellulose (HPC).

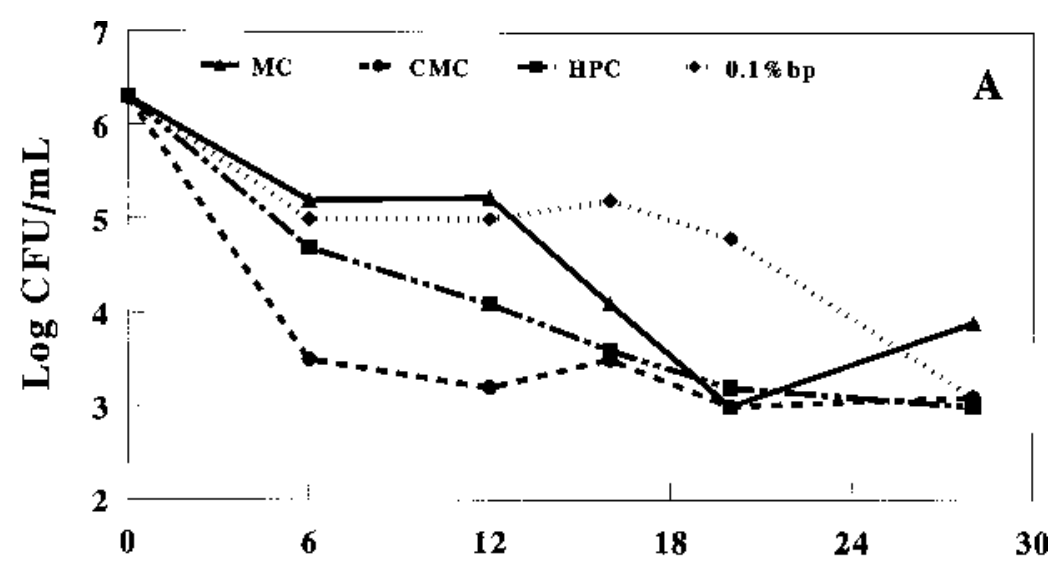

Time (days)

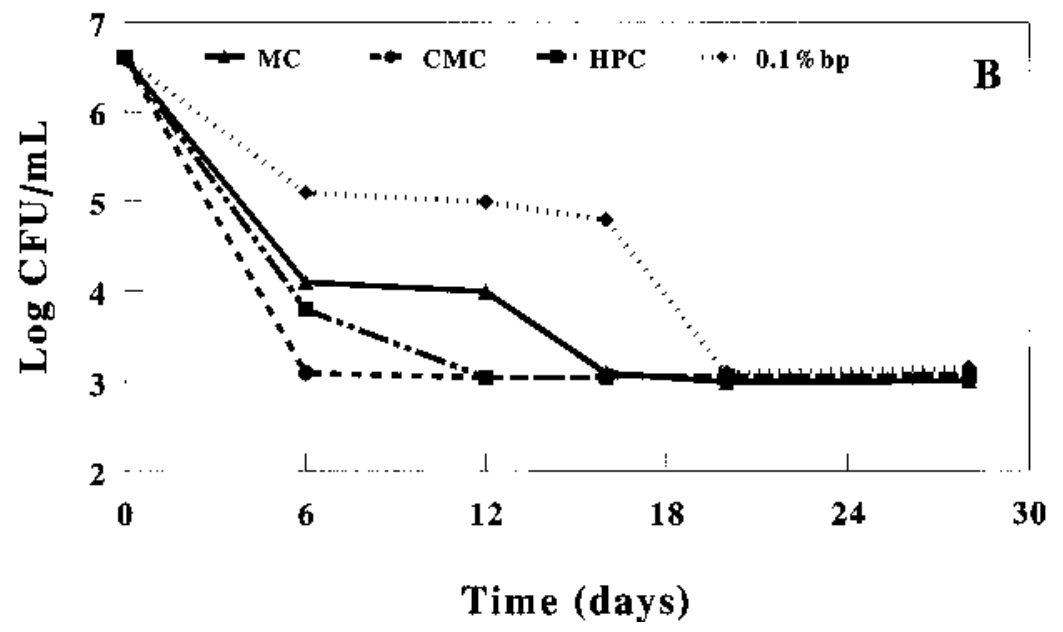

Fig. 2. Recovery at $13 \mathrm{C}$ of (A) Candida guillermondii strain US7 or (B) Debaryomyces sp. strain 230 in dried Nature Seal formulations made with $2 \%$ methylcellulose (MC), carboxymethylcellulose (CMC), or hydroxypropylcellulose (HPC), or in dried $0.1 \%$ bacto-peptone $(0.1 \%$ bp). less decay compared with MC alone, although the difference was not always statistically significant. The MC coating alone did not prevent any decay, although the $\mathrm{SH}$ coating did reduce decay compared with uncoated controls (significant for weeks 2 and 4). The antagonist US7 in MC was effective in reducing decay during the first 2 weeks, and 230 in MC showed significantly less decay than uncoated controls only in the second week. Microorganisms occurring naturally on the surface of the unwashed-uncoated fruit had antagonistic activity for the first 2 weeks of storage relative to washed-uncoated fruit (significant for the second week where unwashed-uncoated had $19.3 \%$ decay vs. $30.4 \%$ for washed-uncoated), as has been reported by Chalutz and Wilson (1990). Postharvest treatments may predispose fruit to decay through an alteration of their surface microflora (Wilson, 1989).

The loss in antagonistic effect during storage may be attributable to the change in pathogens responsible for the decay. In the first week, Penicillium was responsible for all decay. After 4 weeks of storage, however, $61 \%$ of all decay was attributed to stem-end rot, incited by Phomopsis citri Fawc. Unlike Penicillium, this fungus does not develop in wounds, but infects the button (remnant stem/calix) of the fruit preharvest and develops as the button senesces after harvest (Brown and Wilson, 1968). Residue SOPP (from the packinghouse fruit wash procedure) in wound sites may have had an effect on yeast as well as pathogen populations. There was no statistical difference in decay control for imazalil in MC vs. SH coatings.

The efficacy of US7 in coatings with MC also was evaluated on 'Valencia' orange fruit and the results mirrored those with 'Pineapple' (Table 2). In this experiment, US7 was also applied as an aqueous suspension to determine the advantage or disadvantage of combining the antagonist in a coating, using washed-uncoated fruit as controls. Coating made with $\mathrm{MC}$ alone was again ineffective in reducing decay compared with washeduncoated fruit. For the entire 4 weeks of storage, all treatments, except MC alone, resulted in significantly less in decay than evident on the washed-uncoated controls. After 4 weeks, the US7 treatments were not significantly different from treatments containing imazalil in decay control. Although US7 in MC with added nutrients resulted in consistently lower levels of decay compared to the other US7 treatments, the differences were nonsignificant. Therefore, MC coating alone did not help nor hinder the antagonistic activity of the yeasts. This result differs from the case of chemical fungicides, where more fungicide is needed when combined with fruit waxes to equal the decay control of fungicide applied alone (Brown, 1984). McLaughlin (1990) reported that calcium chloride can significantly increase the amount of decay control obtained with US7 by causing a reduction of conidial germination and germ-tube elongation of the pathogen. However, calcium chloride in the absence of the antagonist does not facilitate significant reduction of disease. 
Table 1. Incidence of decay (percent $)^{\mathrm{z}}$ in 'Pineapple' oranges stored at $16 \mathrm{C}$ with $90 \%$ relative humidity.

\begin{tabular}{lcccc}
\hline \hline & \multicolumn{4}{c}{ Time in storage } \\
\cline { 2 - 5 } & \multicolumn{4}{c}{ Percentage of fruit showing decay } \\
\cline { 2 - 5 } Treatment $^{\mathrm{y}}$ & 1 Week & 2 Weeks & 3 Weeks & 4 Weeks \\
\hline NS/MC (2\%) & $5.5 \mathrm{a}$ & $27.0 \mathrm{a}$ & $47.5 \mathrm{a}$ & $66.0 \mathrm{a}$ \\
NS/MC + US7 & $0.5 \mathrm{~b}$ & $12.0 \mathrm{~b}$ & $34.0 \mathrm{~b}-\mathrm{d}$ & $59.0 \mathrm{a}$ \\
NS/MC + 230 & $6.5 \mathrm{a}$ & $19.5 \mathrm{~b}$ & $39.5 \mathrm{a}-\mathrm{c}$ & $53.0 \mathrm{bc}$ \\
NS/MC + I & $4.0 \mathrm{ab}$ & $9.2 \mathrm{~b}$ & $21.6 \mathrm{~d}$ & $32.4 \mathrm{~d}$ \\
SH & $5.6 \mathrm{ab}$ & $16.0 \mathrm{~b}$ & $31.2 \mathrm{~b}-\mathrm{d}$ & $47.6 \mathrm{c}$ \\
SH + I & $3.2 \mathrm{ab}$ & $9.2 \mathrm{~b}$ & $25.6 \mathrm{~cd}$ & $43.2 \mathrm{~cd}$ \\
UC & $10.0 \mathrm{a}$ & $30.4 \mathrm{a}$ & $47.2 \mathrm{ab}$ & $60.8 \mathrm{ab}$ \\
\hline
\end{tabular}

${ }^{2}$ Mean separation within columns according to Duncan's multiple range test $(P \leq 0.05)$. Data are means of four to five boxes of 50 fruit each.

yOranges were coated with Nature Seal (NS) formulated with methylcellulose (MC) and incorporating the yeast Candida guillermondii strain US7 (NS/MC + US7), incorporating the yeast Debaryomyces sp. strain 230 (NS/MC + 230), the fungicide imazalil at $2000 \mathrm{mg} \cdot \mathrm{liter}^{-1}(\mathrm{NS} / \mathrm{MC}+\mathrm{I})$, or the commercial shellac-based citrus wax FMC 360HS (SH), the shellac wax with imazalil at $2000 \mathrm{mg}^{\circ} \cdot \mathrm{liter}^{-1}(\mathrm{SH}+\mathrm{I})$, or they were left uncoated (UC).

Table 2. Incidence of decay (percent) ${ }^{2}$ in 'Valencia' orange stored at $16 \mathrm{C}$ with $90 \%$ relative humidity.

\begin{tabular}{lcccc}
\hline & \multicolumn{4}{c}{ Time in storage } \\
\cline { 2 - 5 } & \multicolumn{4}{c}{ Percentage of fruit showing decay } \\
\cline { 2 - 5 } Treatment $^{\mathrm{y}}$ & 1 Week & 2 Weeks & 3 Weeks & 4 Weeks \\
\hline NS/MC (2\%) & $3.6 \mathrm{ab}$ & $13.6 \mathrm{a}$ & $22.8 \mathrm{a}$ & $26.4 \mathrm{a}$ \\
NS/MC + US7 & $2.8 \mathrm{~b}$ & $7.6 \mathrm{~b}$ & $14.0 \mathrm{~b}$ & $17.6 \mathrm{bc}$ \\
NS/MC + US7 + N & $0.4 \mathrm{~b}$ & $4.0 \mathrm{~b}$ & $11.2 \mathrm{~b}-\mathrm{d}$ & $16.8 \mathrm{c}$ \\
NS/MC + I & $1.2 \mathrm{~b}$ & $3.6 \mathrm{~b}$ & $5.6 \mathrm{~d}$ & $7.2 \mathrm{~d}$ \\
US7 & $2.8 \mathrm{~b}$ & $7.6 \mathrm{~b}$ & $13.6 \mathrm{bc}$ & $18.0 \mathrm{bc}$ \\
SH + I & $1.2 \mathrm{~b}$ & $3.6 \mathrm{~b}$ & $7.6 \mathrm{~cd}$ & $11.2 \mathrm{~cd}$ \\
UC & $6.8 \mathrm{a}$ & $16.8 \mathrm{a}$ & $23.2 \mathrm{a}$ & $26.8 \mathrm{a}$ \\
\hline
\end{tabular}

${ }^{2}$ Mean separation within columns according to Duncan's multiple range test $(P \leq 0.05)$. Data are means of four to five boxes of 50 fruit each.

${ }^{y}$ Oranges were coated with Nature Seal (NS) formulated with methylcellulose (MC) and incorporating the yeast Candida guillermondii strain US7 (NS/MC + US7), US7 and nutrients $0.2 \%$ glucose and $0.22 \%$ calcium chloride (NS/MC + US7 $+\mathrm{N})$, the fungicide imazalil at $2000 \mathrm{mg} \cdot \mathrm{lite}^{-1}(\mathrm{NS} / \mathrm{MC}+\mathrm{I})$, or an aqueous suspension of US7 (US7), the commercial shellac-based citrus wax FMC 360HS with imazalil at 2000 $\mathrm{mg} \cdot \mathrm{liter}^{-1}(\mathrm{SH}+\mathrm{I})$, or they were left uncoated (UC).

'Valencia' oranges exhibited less decay than 'Pineapple' fruit. 'Pineapple' oranges are known for susceptibility to decay, especially from Penicillium infection, due either to increased susceptibility to peel injury or because they are harvested earlier in the season when the Penicillium inoculum is higher (Eldon Brown, personal communication). Penicillium accounted for all decay of 'Valencia' oranges during the first 2 weeks of storage, and stemend rot only appeared in the third and fourth weeks. After 4 weeks of storage, $13.9 \%$ of all 'Valencia' orange decay was attributed to stemend rot. As with 'Pineapple' oranges, imazalil was compatible with both types of coatings.

Recovery of yeasts from the surface of oranges. The population of US7 on the surface of stored 'Valencia' oranges dropped at least one log step for all US7-treated fruit after 1 day at $16 \mathrm{C}$, followed by a slow increase during the subsequent 20 days (Fig. 3). The greatest drop in populations was for the aqueous suspension of US7 and the least for US7 in coating with $\mathrm{MC}$ and added nutrients. The US7 concentration remained consistently lower on fruit that received the aqueous US7 treatment compared with fruit treated with US7 in MC. On 'Pineapple' oranges, antagonist population decreased similarly (about one log step) after 2 days for US7 and 230 applied to fruit in coatings made with MC (data not shown). This rapid decrease was probably not due to the heat used to dry the coating on the fruit, since a similar decrease was found for US7 and 230 in air-dried coatings on disks. The recovery was initially slightly higher in the coatings with $0.2 \%$ glucose and $0.22 \%$ calcium chloride, but there was no difference compared with coatings without added nutrients after 7 days (Fig. 3). The recovery of US7 applied in water was lower than when applied in MC coatings, suggesting that MC enhances survival of US7. Some yeasts, including some in the genera Candida, can use xylan as a carbon source and can convert xylose to ethanol (Biely, 1990). Perhaps the yeasts in this study were able to use MC as a source of nutrients.

During the 21 days of storage, a yeast population of at least $10^{4} \mathrm{cfu} / \mathrm{cm}^{2}$ was maintained on the surface of uncoated fruit, with higher populations when the yeast was applied in MC coatings. According to McGuire (1994), a minimum population of $10^{5} \mathrm{cfu} / \mathrm{cm}^{2}$ is required for a significant control of $P$. digitatum by US7. 'Valencia' fruit, however, treated with US7 in MC coatings, were similar in decay percentage to fruit treated with US7 in aqueous suspension, where the yeast population had dropped below $10^{5} \mathrm{cfu} / \mathrm{cm}^{2}$ after 1 day (Fig. 3). Only fruit treated with US7 in MC with added nutrients showed consistently lower levels of decay than those treated with aqueous US7 and these differences were not statistically significant.

Colonies of various yeasts and molds were isolated from the surface of the coated stored oranges (data not shown). A change in microflora occurred during storage. In all treat- ments, Penicillium digitatum predominated after 1 week, whereas after 2 weeks other fungi and yeasts appeared (including P. italicum, Aspergillus niger v. Tiegh., Cladosporium sp. and unidentified yeasts). An analysis of microorganism populations on the surface of stored 'Valencia' orange fruit was conducted after 3 weeks of storage. No significant differences were found in concentration of microorganisms (excluding US7) on the surface of oranges between MC coating treatments with and without US7 $\left(1.5 \times 10^{4} \mathrm{cfu} / \mathrm{cm}^{2}\right.$ for coating alone and ranging from $4.3 \times 10^{3}$ to $3.1 \times 10^{5}$ $\mathrm{cfu} / \mathrm{cm}^{2}$ for coating treatments with US7). Similar results were observed for 'Pineapple' oranges.

\section{Conclusions}

A coating formulation made with $\mathrm{MC}$ was the best carrier for pathogen antagonist yeasts US7 and 230. However, the coating with yeast must be applied to the fruit within a few hours after preparation to obtain a yeast population on the fruit surface that can be effective in disease control. Coatings made with CMC were incompatible with US7 and 230. The incompatibility may be due to a direct toxic effect of the coating on the yeasts, to the inability of the antagonists to use CMC as a nutrient source, or the inhibitory activity of contaminating microbial populations in CMC coatings. This last hypothesis is not likely, as the dried coating kept at $13 \mathrm{C}$ showed no heavy contamination with gram-negative rods yet had the same low antagonist recovery. Coatings made with $\mathrm{MC}$ had a lower $\mathrm{pH}$ (3.0) than those with CMC ( $\mathrm{pH}$ 6.0), which may have made the MC coating semi-selective for the antagonist yeasts. However, HPC with the same low $\mathrm{pH}$ and no microbial contamination showed a lower antagonist recovery than MC. This result suggests that the antagonists were able to use certain cellulose derivatives (i.e., $\mathrm{MC}$ ) as a source of nutrients better than others.

The approach taken in this study was to incorporate the antagonist without making changes in current commercial packinghouse practices. The decay control offered by US7 appeared to be improved by using a coating made with MC and added nutrients as a carrier, but this effect was not statistically significant. There was neither a qualitative nor a quantitative difference in the pathogen population, although incidence of decay was reduced.

The survival of US7 in coatings made with $\mathrm{MC}$, together with the efficacy of this antagonist in protecting naturally infected oranges (coated, packed, and stored under conditions practiced by the industry), suggest that such a system might be achievable under commercial conditions. This finding increases the potential applicability of US7, or other antagonist yeasts, for reducing postharvest diseases of oranges. There is concern, however, that some strains of this species, which can grow at 37C, are potentially human pathogens. Preliminary tests on strain US7 do not support this threat (McLaughlin et al., 1992), but further toxicological studies are required before product development will proceed. 


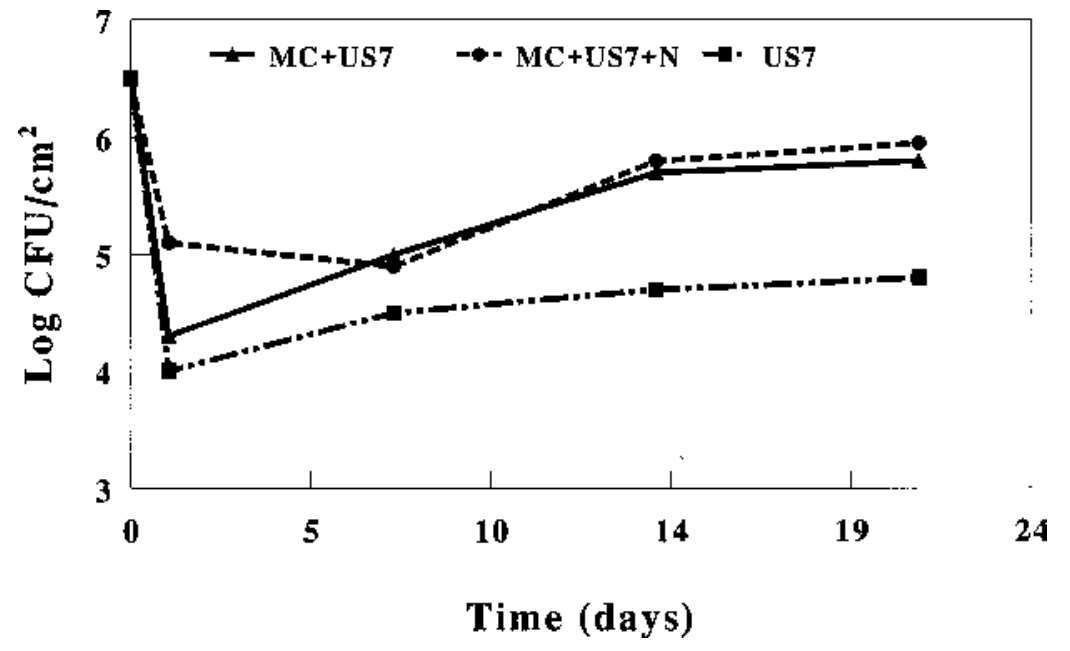

Fig. 3. Recovery at 16C of Candida guillermondii strain US7 from the surface of stored 'Valencia' orange fruit coated with Nature Seal formulations made with $2 \%$ methylcellulose and inoculated with US7 (MC + US7), inoculated with US7 with added nutrients $0.2 \%$ glucose and $0.22 \%$ calcium chloride (MC + US7 $+\mathrm{N}$ ), or treated with an aqueous suspension of US7 (US7).

Finally, cellulose coatings provide an attractive sheen to citrus fruit and, along with the yeast, can be washed off with water. They do not add the degree of shine provided by shellac-type waxes nor do they prevent weight loss as effectively as shellac coatings. However, improvements have been made in water barrier properties of Nature Seal coatings since this experiment was conducted. With shellacbased coatings, however, there may be a tradeoff between shine/water loss control and creation of anaerobic conditions in fruit that may lead to off flavor (Baldwin, 1994; Davis and Hofmann, 1973; Hagenmaier and Baker, 1993). Polysaccharide coatings, such as Nature Seal, are more permeable to gases than shellac waxes (Baldwin et al., 1995; Hagenmaier and Shaw, 1992; Kester and Fennema, 1988) and, therefore, are less likely to cause anaerobic conditions.

\section{Literature Cited}

Baldwin, E.A. 1994. Edible coatings for fresh fruits and vegetables: Past, present, and future, p. 2564. In: J.M. Krochta, E.A. Baldwin, and M.O. Nisperos-Carriedo (eds.). Edible coatings to improve food quality. Technomic Publ. Co., Lancaster, Pa.

Baldwin, E.A., M.O. Nisperos, P.E. Shaw, and J.K. Burns. 1995. Effect of coatings and prolonged storage conditions on fresh orange flavor volatiles, degrees brix, and ascorbic acid levels.
J. Agr. Food Chem. 43:1321-1331.

Bancroft, M.N., P.D. Gardner, J.W. Eckert, and J.L. Baritelle. 1984. Comparison of decay control strategies in California lemon packing houses. Plant Dis. 68:34-28.

Biely, P. 1990. Xylan, pectin and cellulose utilization by yeasts. Zentralbl. Mikrobiol (Hungary) 145:344.

Brown, G.E. 1984. Efficacy of citrus postharvest fungicides applied in water or resin solution or water wax. Plant Dis. 68:415-418.

Brown, G.E. and W.C. Wilson. 1968. Mode of entry of Diplodia natalensis and Phomopsis citri into Florida oranges. Phytopathology 58:736-739.

Chalutz, E. and C.L. Wilson. 1990. Postharvest biocontrol of green and blue mold and sour rot of citrus fruit by Debaryomyces hansenii. Plant Dis. 74:134-137.

Davis, P.L. and R.C. Hofmann. 1973. Effects of coatings on weight loss and ethanol buildup in juice of oranges. J. Agr. Food Chem. 21:455458.

Droby, S., E. Chalutz, L. Cohen, B. Weiss, and C.L. Wilson. 1990. Biological control of postharvest diseases of citrus fruit, p. 114-120. In: C.L. Wilson and E. Chalutz (eds.). Biological control of postharvest diseases of fruits and vegetables, Wkshp. Proc. U.S. Dept. of Agr.-Agr. Res.

Droby, S., E. Chalutz, C.L. Wilson, and M. Wisniewski. 1989. Characterization of the biocontrol activity of Debaryomyces hansenii in the control of Penicillium digitatum on grapefruit. Can. J. Microbiol. 35:794-800.

Hagenmaier, R.D. and R.A. Baker. 1993. Reduction Serv., ARS-92. in gas exchange of citrus fruit by wax coatings. J. Agr. Food Chem. 41:283-287.

Hagenmaier, R.D. and P.E. Shaw. 1992. Gas permeability of fruit coating waxes. J. Amer. Soc. Hort. Sci. 117:105-109.

Huang, Y., B.L. Wild, and S.C. Morris. 1992. Postharvest biological control of Penicillium digitatum decay on citrus fruit by Bacillus pumilus. Ann. Appl. Biol. 120:367-372.

Kester, J.J. and O.R. Fennema. 1988. Edible coatings: A review. Food Technol. 42:47-59.

McGuire, R.G. 1994. Application of Candida guilliermondii in commercial citrus coatings for biocontrol of Penicillium digitatum on grapefruits. Biol. Control 4:1-7.

McLaughlin, R.J. 1990. A review and current status of research on enhancement of biological control of postharvest diseases of fruits by use of calcium salts with yeasts, p. 184-195. In: C.L. Wilson and E. Chalutz (eds.). Biological control of postharvest diseases of fruits and vegetables, Wkshp. Proc. U.S. Dept. of Agr.-Agr. Res. Serv., ARS-92.

McLaughlin, R.J., C.L. Wilson, E. Chalutz, C.P. Kurtzman, W.F. Fett, and S.F. Osman. 1990. Characterization and reclassification of yeasts used for biological control of postharvest diseases of fruits and vegetables. Appl. Environ. Microbiol. 56:3583-3586.

McLaughlin, R.J., C.L. Wilson, S. Droby, R. BenArie, and E. Chalutz. 1992. Biological control of postharvest diseases of grape, peach, and apple with the yeasts Kloeckera apiculata and Candida guilliermondii. Plant Dis. 76:470-473.

Nisperos-Carriedo, M.O. and E.A. Baldwin. 1993, 1994. Increasing stability of fruits, vegetables or fungi. U.S. patent no. 5,198,254, 30 Mar. 1993; 5,376,043, 27 Dec. 1994.

Singh, N. and B.J. Deverall. 1984. Bacillus subtilis as a control agent against fungal pathogens of citrus fruit. Trans. British Mycol. Soc. 83:487490.

Smilanick, J.L. and R. Denis-Arrue. 1992. Control of green mold of lemons with Pseudomonas species. Plant Dis. 76:481-485.

Waks, J., M. Schiffmann-Nadel, E. Lomaniec, and E. Chalutz. 1985. Relation between fruit waxing and development of rots in citrus fruit during storage. Plant Dis. 69:869-870.

Wilson, C.L. 1989. Managing the microflora of harvested fruits and vegetables to enhance resistance. Phytopathology 79:1387-1390.

Wilson, C.L. and E. Chalutz. 1989. Postharvest biological control of Penicillium rots of citrus with antagonistic yeasts and bacteria. Sci. Hort. 40:105-112.

Wilson, C.L., M.E. Wisniewski, C.L. Biles, R. McLaughlin, E. Chalutz, and S. Droby. 1991. Biological control of post-harvest diseases of fruits and vegetables: Alternatives to synthetic fungicides. Crop Protection 10:172-177. 